\title{
Ramularia mali strains isolated from petroleum product-contaminated soil are capable to grow on multiple aromatic compounds
}

\author{
WATUMESA A. TAN", HELEN SURYA TEJA, STEPHANIE \\ Faculty of Biotechnology, Universitas Katolik Atma Jaya Indonesia. Jl. Raya Cisauk-Lapan No. 10, Kampus BSD, Tangerang 15345, Banten, Indonesia. \\ Tel.: +62-21-80827200, `email: tan.watumesa@atmajaya.ac.id
}

Manuscript received: 3 February 2020. Revision accepted: 16 July 2020.

\begin{abstract}
Tan WA, Teja HS, Stephane. 2020. Ramularia mali strains isolated from petroleum product-contaminated soil are capable to grow on multiple aromatic compounds. Biodiversitas 21: 3590-3595. Aromatic compounds are present as a complex mixture in the environment, some of which are toxic and carcinogenic in humans and animals. In this study, we reported the first instance of arthroconidial yeast growth on more than one aromatic compound. Yeasts were isolated from soil surrounding gas stations and screened for growth on phenol, followed by qualitative growth testing on chlorobenzene, aniline, toluene, 2-nitrotoluene, benzoate, and naphthalene. Pure isolates identity and phylogeny were determined based on the ITS region. All isolates grew on phenol and benzoate, but none grew on naphthalene. Aside from the inability to grow on naphthalene, SR8 grew on other tested aromatics, while SR3 showed similar growth ability except on 2-nitrotoluene. Growth on 2-nitrotoluene was observed for PPS3, PB4, SR1, SR6, and SR8, a phenotype that has yet been reported in yeasts thus far. All isolates shared 99.81-100\% similarity and were phylogenetically clustered with the arthroconidial yeast Ramularia mali CBS 129581, despite that some of them were morphologically different and had varying capability to grow on tested aromatics. Therefore, ITS sequences cannot be used to differentiate Ramularia mali up to the strain level. Overall, we demonstrated the diverse potential of yeast strains in reducing aromatic compound contamination.
\end{abstract}

Keywords: Aromatic compounds, arthroconidial yeasts, biodegradation, bioprospecting

\section{INTRODUCTION}

Aromatic compounds consist of one or more benzene rings that may be attached to one or more substituted groups. Various aromatic compounds exist as a complex mixture and can be found in nature, such as components of fossil fuels and as plant exudates. Some of them are also prevalent as xenobiotics and may be introduced to the environment due to anthropogenic activities. They may potentially be carcinogenic in humans or classified as priority pollutants due to their toxicity (Seo et al. 2009; Gami et al. 2014). Therefore, effective and efficient ways to remove harmful aromatic compounds from the environment and from waste are important.

There are several ways to decontaminate aromatic compounds, including chemical and physical treatments using activated carbon adsorption, ion exchange, liquidliquid extraction, and chemical oxidation. However, these methods are considered less efficient, especially in terms of costs, and they may also result in hazardous byproducts, a phenomenon is known as secondary pollution. Another alternative is through biodegradation, in which microbes are able to assimilate aromatic compounds to promote their growth in situ or $e x$-situ. This method is considered a more environmentally friendly and cost-effective alternative (AlKhalid and El-Naas 2012).

Biodegradation may involve bacteria, filamentous fungi, or yeasts, for which phenol is degraded aerobically through similar pathways (reviewed in Sridevi et al. 2012). The first step of aromatic compound degradation is catalyzed by the ring hydroxylating monooxygenase or dioxygenase to form catechol or its derivatives. Catechols either go through ortho- or meta- cleavage by catechol 1,2or catechol 2,3-dioxygenase, respectively. As an exception, the meta-pathway is to date lacking in yeasts (Schülter and Schauer 2017). The resulting compounds then go through subsequent steps to produce acetyl-CoA and succinate, both of which are incorporated into the tricarboxylic acid (TCA) or Krebs cycle (Sridevi et al. 2012).

Compared to bacteria, information on diversity of yeasts that can degrade aromatic compounds is still quite rare. In the past, yeast species that have been reported to degrade phenol were limited to Candida maltosa (Fialova et al. 2004), C. tropicalis (Salmeron-Alcocer et al. 2007), C. albicans, Rhodotorula glutinis, Cryptococcus humicola (Schülter and Schauer 2017), Trichosporon asahii (Cong et al. 2014), Pichia guilliermondii and Meyerozyma guilliermondii (Karimia and Hassanshahian 2016). The utilization of yeasts over bacteria or fungi is also of advantage due to their extensive physicochemical tolerance and tough cell walls, wide $\mathrm{pH}$ tolerance between 3 and 9 , survival mechanism from freezing temperatures to that over $40^{\circ} \mathrm{C}$, and wide tolerance of osmolarity or ionic strength (Walmsley and Keenan 2012). Despite that, as in other microorganisms, the bioavailability of hydrophobic aromatic compounds is a limiting factor for biodegradation in yeasts (Whang et al. 2009).

Therefore, in this study, we isolated yeasts from soil contaminated with petroleum products, that had the ability to grow on various aromatic compounds. In addition to our 
effort in revealing the plethora of local yeast diversity, isolates obtained in this study can potentially be used to eliminate or reduce levels of aromatic compounds in contaminated environment.

\section{MATERIALS AND METHODS}

\section{Culture media}

Yeast Peptone Dextrose (YPD) was used as enrichment medium for isolation and cultivation (10 g yeast extract, 20 $\mathrm{g}$ peptone, and $20 \mathrm{~g}$ dextrose per liter medium). Phenol (1 $\mathrm{g} / \mathrm{L}$ ) was added to medium to screen for yeast isolates, and chloramphenicol $(50 \mathrm{mg} / \mathrm{L})$ was supplemented into the medium to suppress bacterial growth.

Initial screening for phenol-degrading ability was carried out on Mineral Salt Medium Agar (MSM Agar) as described by Walker (1973), which contains $3 \mathrm{~g}$ $\left(\mathrm{NH}_{4}\right)_{2} \mathrm{SO}_{4}, 0.7 \mathrm{~g} \quad \mathrm{MgSO}_{4} .7 \mathrm{H}_{2} \mathrm{O}, 0.6 \mathrm{~g} \mathrm{NaCl}, 0.4 \mathrm{~g}$ $\mathrm{Ca}\left(\mathrm{NO}_{3}\right)_{2} .4 \mathrm{H}_{2} \mathrm{O}, 1 \mathrm{~g} \mathrm{~K}_{2} \mathrm{PO}_{4}, 0.2 \mathrm{~g} \mathrm{~K}_{2} \mathrm{HPO}_{4}$, and $1 \mathrm{mg} \mathrm{Fe}-$ (III)-EDTA per liter medium. Phenol vapor was supplemented in Durham tubes filled with sterile cotton ball, taped on the lid of the petri dish. All isolates were further maintained on YPD agar (solidified with $1.5 \%$ bacteriological agar (Difco).

\section{Isolation of phenol-degrading yeasts}

Phenol-degrading yeasts were isolated from petroleum product-contaminated soil collected from four locations (BSD, Pahlawan Seribu, and two locations at Rawabuntu) surrounding the area of Bumi Serpong Damai gas station, Tangerang, Banten using a method described by Ashliha and Alami (2014) with modifications. Soil samples were incubated at $4^{\circ} \mathrm{C}$ overnight to slow down growth of potential competing bacteria. One gram of soil was inoculated to liquid YPD supplemented with phenol $(1 \mathrm{~g} / \mathrm{L})$ and chloramphenicol $(50 \mathrm{mg} / \mathrm{L})$, and incubated at $28^{\circ} \mathrm{C}$, $150 \mathrm{rpm}$ for 3 days. Serial dilution of the cultures was prepared $\left(10^{-6}, 10^{-7}\right.$, and $\left.10^{-8}\right)$ and $0.1 \mathrm{~mL}$ of each dilution was spread on MSM agar containing phenol vapor as a single carbon source. All cultures were incubated at $28^{\circ} \mathrm{C}$ for approximately 3-5 days until single colonies appear. Single colonies were further transferred to MSM agar supplemented with phenol vapor 3-4 times to obtain pure isolates.

\section{Growth test on various aromatic compounds}

Phenol-degrading yeast colonies were tested for growth on various aromatic compounds, including the naturallyoccurring monoaromatics (i.e. phenol, aniline, toluene, and benzoate), artificial monoaromatics (i.e. chlorobenzene and 2-nitrotoluene), and polyaromatic (i.e. naphthalene). The hydrophobicity of all tested compounds was calculated using ALOGPS 2.1 (Tetko et al. (2005); http://vcclab.org/lab/alogps/) The colonies were grown on the MSM agar supplemented with aromatic compound vapor (toluene, chlorobenzene, 2-nitrotoluene, and aniline) in a Durham tube taped on the lid of the petri dish, except for benzoate and naphthalene. Instead, $10 \mathrm{mM}$ sodium benzoate was added to the agar, while 0.1 grams naphthalene crystals were added to the lid of the petri dish due to its insolubility. All cultures were incubated at $28^{\circ} \mathrm{C}$ for 3 days.

\section{Molecular identification of yeasts}

All isolates were molecularly identified based on the ITS region. Genomic DNAs were extracted using a lithium acetate-based method as described by Lõoke et al. (2011). The primer pair ITS1 (5'-TCC GTA GGT GAA CCT GCG G-3') and ITS4 (5'-TCC TCC GCT TAT TGA TAT GC3') were used to amplify the 5.8S rDNA-ITS region (Heras-Vazquez et al. 2003). PCR reactions contained 12.5 $\mu \mathrm{L}$ GoTaq ${ }^{\circledR}$ Green Master Mix $2 \times, 10 \mu \mathrm{M}$ primer each, 100 ng DNA template and nuclease-free water to make up $25 \mu \mathrm{L}$ reaction volume. The PCR cycles were as follow: pre-denaturation at $94^{\circ} \mathrm{C}$ for 5 minutes; 35 cycles of denaturation at $94^{\circ} \mathrm{C}$ for 30 seconds, annealing at $51^{\circ} \mathrm{C}$ for 30 seconds, elongation at $72^{\circ} \mathrm{C}$ for 1 minute; and postelongation at $72^{\circ} \mathrm{C}$ for 5 minutes. PCR products were confirmed using agarose gel electrophoresis and sent for sequencing First Base, Singapore. The sequences were compared to GenBank database (www.ncbi.nlm.nih.gov) using BLASTN (Basic Local Alignment Search Tool Nucleotide-Nucleotide). Multiple sequence alignment was conducted using ClustalW (Thompson et al. 1994), followed by phylogenetic analysis using MEGAX based on the Neighbor-Joining algorithm (Kumar et al. 2018).

\section{RESULTS AND DISCUSSIONS}

\section{Morphology of yeast colonies}

A total of 15 yeast isolates were obtained from soil collected from four gas stations, coded as SR and PR (soil from two different gas stations at Rawabuntu), PPS (Pahlawan Seribu), and PB (Bumi Serpong Damai). All colonies were round and small in size $(<1 \mathrm{~mm})$. A majority of the isolates were translucent and white, except for isolate SR7 and SR9, which were opaque cream-colored, and SR8, which was yellow in color (Figure 1).

\section{Growth test on various aromatic compounds}

The tested aromatic compounds used in this study were chosen to represent various aromatic compound groups, including the naturally-occurring substituted monoaromatics (i.e. phenol, aniline, toluene, and benzoate), artificial substituted monoaromatics (i.e. chlorobenzene and 2-nitrotoluene), and polyaromatic (i.e. naphthalene). Growth capability of yeast isolates obtained in this study is presented in Table 1. The ability to grow on phenol and benzoate were evident for all isolates, but none grew on naphthalene. Most notably, isolate SR8 and SR3 were able to grow on all tested monoaromatic compounds, except that the latter did not grow on 2-nitrotoluene. 


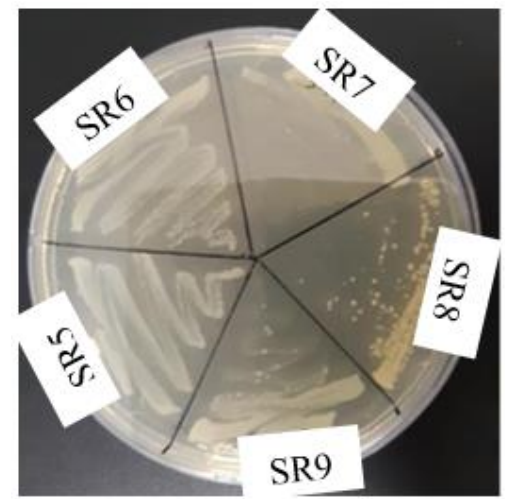

A

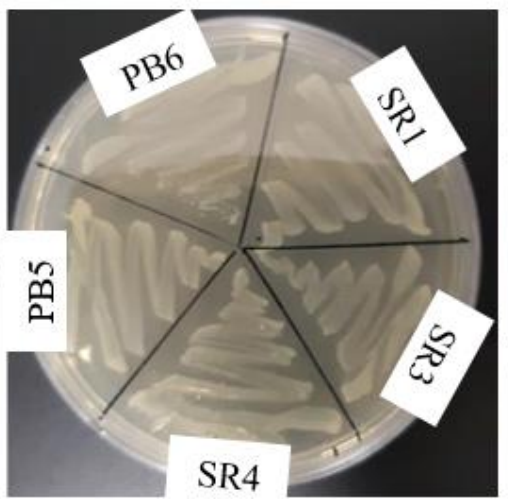

B

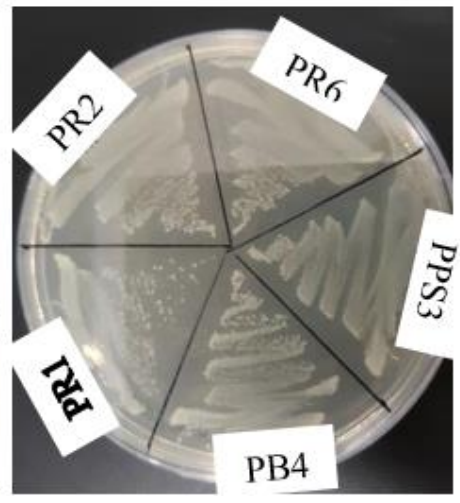

C

Figure 1. The morphology of yeast colonies on minimal agar supplemented with phenol vapor. A. SR5, SR6, SR7, SR8, SR9; B. PB5, PB6, SR1, SR3, SR4; C. PR1, PR2, PR6, PPS3, PB4

Table 1. Growth of yeast isolates on aromatic compounds

\begin{tabular}{|c|c|c|c|c|c|c|c|}
\hline \multirow{2}{*}{ Isolate } & \multicolumn{7}{|c|}{ Aromatic compounds } \\
\hline & Phenol & Chlorobenzene & Aniline & Toluene & 2-Nitrotoluene & Benzoate & Naphthalene \\
\hline PR1 & ++ & - & - & - & - & + & - \\
\hline PR2 & +++ & - & - & - & - & + & - \\
\hline PR6 & +++ & - & - & - & - & + & - \\
\hline PPS3 & +++ & - & - & - & + & ++ & - \\
\hline PB4 & +++ & - & - & - & + & + & - \\
\hline PB5 & +++ & - & - & - & - & + & - \\
\hline PB6 & +++ & - & - & - & - & + & - \\
\hline SR1 & +++ & - & - & - & + & + & - \\
\hline SR3 & +++ & ++ & ++ & ++ & - & +++ & - \\
\hline SR4 & +++ & - & - & - & - & + & - \\
\hline SR5 & +++ & - & - & - & - & + & - \\
\hline SR6 & +++ & - & - & - & + & + & - \\
\hline SR7 & + & - & - & - & - & + & - \\
\hline SR8 & + & +++ & +++ & +++ & ++ & +++ & - \\
\hline SR9 & ++ & - & - & - & - & + & - \\
\hline
\end{tabular}

Note: Growth level was rated based on the thickness of yeast lawn from the thickest (+++) to thinnest (+), or no growth (-)

Growth capability on aromatic compounds may be limited by the toxic nature of these compounds to yeast cells. Aromatic compounds can bind to the lipid bilayer membrane, thus compromising cellular integrity, and this is correlated to the hydrophobicity of their structure (Heipieper and Martínez 2010). As demonstrated in other microorganisms, aromatic compound catabolism is, to a certain extent, a part of the defense mechanism against the toxicity of these compounds (Seo et al. 2009; Mäkelä et al. 2015). We calculated the hydrophobicity $(\log \mathrm{P})$ of all tested aromatic compounds using ALOGPS 2.1 (http://vcclab.org/lab/alogps/), revealing the order of the tested compound from most hydrophobic to least hydrophobic: naphthalene (3.33) > chlorobenzene (2.78) > toluene (2.56) > 2-nitrotoluene (2.32) > phenol (1.39) > benzoate (1.12) > aniline (0.89). As the most hydrophobic among all compounds, naphthalene may be most toxic compared to other tested compounds. This explains why none of the yeast isolates grew on naphthalene. In addition, all isolates were able to grow on phenol and benzoate, both of which are less hydrophobic among tested compounds.

On the other hand, growth capability on aromatic compounds is determined by the availability of enzyme(s) required for their degradation. Microbial growth on more than one aromatic compounds has been reported previously, and this is partly due to the versatility of hydroxylating enzymes involved in the initial step of aromatic compound degradation. For example, the toluene dioxygenase from Pseudomonas putida F1 facilitates the oxidation of more than 200 different substrates (Boyd et al. 2001). Similarly, the P450 monooxygenase of the white-rot fungi Phanerochaete chrysosporium recognizes various polycyclic aromatic hydrocarbons and alkylphenols (Syed et al. 2013). The broad growth substrates for these microorganisms and our yeast isolates indicate that they may play an important role in the biodegradation of pollutant mixtures such in petroleum or wastewater. Owing to the lack of study on ring hydroxylating enzymes and their substrate specificity in yeasts, it is of importance to 
bring future research towards this direction. More experiments are also needed to test whether SR8 and SR3 able to tolerate and catabolize aromatic compound mixtures.

Interestingly, growth on 2-nitrotoluene was observed for isolate PPS3, PB4, SR1, SR6, and SR8. This is the first study to demonstrate growth of yeast on 2-nitrotoluene. Thus far, such ability has only been reported in two species of bacteria, i.e. Acidovorax sp. JS42 (Haigler et al. 1994) and Micrococcus sp. SMN-1 (Mulla et al. 2011). In bacteria, 2-nitrotoluene is converted to 3-methyl catechol by 2-nitrotoluene-2,3-dioxygenase, which then feeds into the meta-pathway prior to entering the central metabolism (Rabinovitch-Deere and Parales et al. 2012). As to date, the meta-pathway has yet been reported in yeasts, the metabolic pathway involved in 2-nitrotoluene degradation in our yeast isolates remains unclear.

\section{Molecular identification of yeasts and phylogenetic analysis}

BLAST analysis showed that all isolates had the highest match with Ramularia mali CBS 129581 (99.80-100\%) (Table 2). Similarity with other Ramularia species, including $R$. eucalypti and $R$. glenii, was also shown for all isolates, ranging from 99.23-99.61\% (data not shown). Representatives of reference sequences that matched with our isolates were included in the phylogenetic analysis. Five clusters were formed, in which all isolates were clustered with $R$. mali CBS 129581 (Figure 2).

Nevertheless, apparent morphologically different was observed for several isolates, including SR7 and SR9, both of which are opaque and cream-colored, as well as SR8, which was yellow, while others are translucent. In addition, all isolates showed a variety of growth capabilities on aromatic compounds. Altogether this indicates that the isolates obtained in this study belong to different strains of $R$. mali, yet the ITS sequences alone were not sufficient to differentiate such species up to the strain level. According to Bakhshi (2018), for further identification of fungi, four other genes can be targeted, namely, those that encode for actin (actA), translation elongation factor 1- $\alpha$ (tefl), RNA polymerase II second largest subunit (rpb2), and glyceraldehyde-3-phosphate dehydrogenase (gapdh). Therefore, the accuracy and depth of $R$. mali identification may be improved by including one or more of these four genes in addition to ITS.

Ramularia spp. are arthroconidial yeasts, a fungal group that interchanges between yeast and mycelium phase in response to certain environmental factors (Videira et al. 2015). At $30^{\circ} \mathrm{C}$ or higher, the fungi grow in the form of mycelia, and at below $30^{\circ} \mathrm{C}$ it will grow as yeast phase (Wartmann and Kunze 2000; Videira et al. 2015). In this research, all isolates were grown at $28^{\circ} \mathrm{C}$ and therefore they were isolated in yeast form.

Ramularia spp. are also known phytopathogens that cause Ramularia Leaf Spot (RLS) disease in barley, strawberry, eucalyptus, and banana plants (Videira et al. 2016). According to Kulbat (2016), phenolic compounds play a role in plant defense mechanisms against pathogens and oxidative stress-mediated by copper ions. For example, infection by Mycosphaerella fifiensis, the asexual form of Ramularia sp., in banana leaves led to the accumulation of phenolic compounds in areas surrounding the infected lesion (Sanchez-García et al. 2013). Therefore, deficiency or loss of phenolic compounds may pose an advantage for plant pathogens in infecting their hosts (Kulbat 2016). Despite that, to date there is no direct evidence that yeast phase Ramularia can degrade phenol or phenolic compounds.

Overall, this study highlights the first report of diverse Ramularia mali isolated from petroleum productcontaminated soil and their ability to grow on more than one aromatic compound. Further growth and enzymatic characterization are required to assess the extent to which these isolates can degrade aromatic compound mixtures. Not only such information will enrich our knowledge of local yeast biodiversity, but it will also be useful in designing aromatic compound degradation strategies.

Table 2. Highest reference sequence match with aromatic compound-degrading yeast isolates based on the ITS sequences

\begin{tabular}{llll}
\hline Isolate code & Species & Similarity $(\boldsymbol{\%})$ & Accession number \\
\hline PR1 & Ramularia mali CBS 129581 & 100 & KJ504778.1 \\
PR2 & Ramularia mali CBS 129581 & 100 & KJ504778.1 \\
PR3 & Ramularia mali CBS 129581 & 100 & KJ504778.1 \\
PPS3 & Ramularia mali CBS 129581 & 99.81 & KJ504778.1 \\
PB4 & Ramularia mali CBS 129581 & 99.81 & KJ504778.1 \\
PB5 & Ramularia mali CBS 129581 & 99.80 & KJ504778.1 \\
PB6 & Ramularia mali CBS 129581 & 100 & KJ504778.1 \\
SR1 & Ramularia mali CBS 129581 & 99.80 & KJ504778.1 \\
SR3 & Ramularia mali CBS 129581 & 99.81 & KJ504778.1 \\
SR4 & Ramularia mali CBS 129581 & 99.80 & KJ504778.1 \\
SR5 & Ramularia mali CBS 129581 & 100 & KJ504778.1 \\
SR6 & Ramularia mali CBS 129581 & 99.80 & KJ504778.1 \\
SR7 & Ramularia mali CBS 129581 & 99.81 & KJ5047778.1 \\
SR8 & Ramularia mali CBS 129581 & 99.80 & KJ504778.1 \\
SR9 & Ramularia mali CBS 129581 & 99.80 & \\
\hline
\end{tabular}




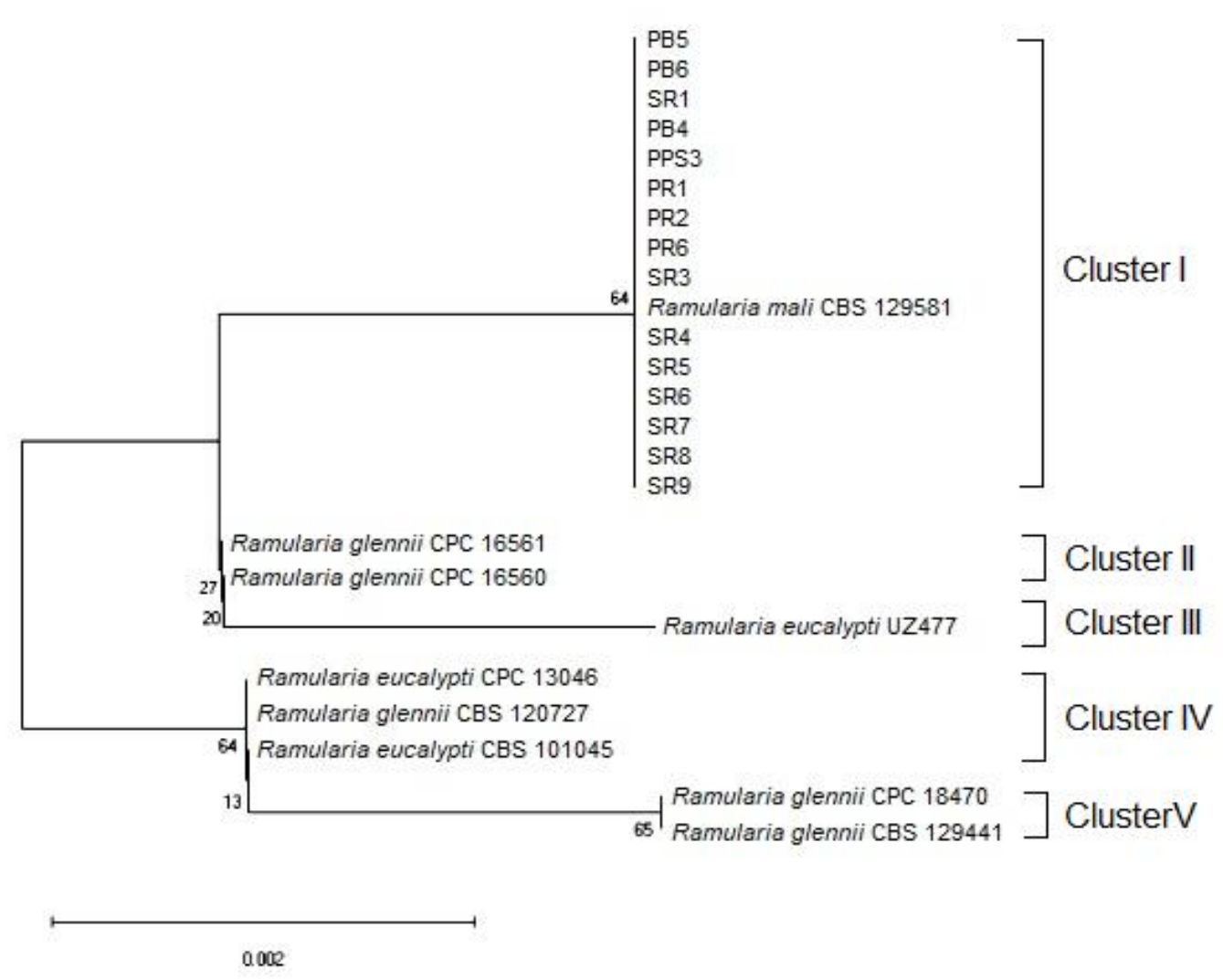

Figure 2. Phylogenetic relationship of aromatic compounds-degrading yeasts and reference Ramularia strains. Neighbor-joining algorithm was employed along with bootstrap analysis in 1000 repeats. The horizontal bar on bottom left indicates genetic distance.

\section{ACKNOWLEDGEMENTS}

This study was funded by the Faculty of Biotechnology, Atma Jaya Catholic University, Jakarta, Indonesia research grant.

\section{REFERENCES}

Al-Khalid T, El-Naas MH. 2012. Aerobic biodegradation of phenols: a comprehensive review. Crit Rev Environ Sci Technol 42: 1631-1690. DOI: 10.1080/10643389.2011.569872.

Ashliha IN, Alami NH. 2014. Karakterisasi khamir dari pulau Poteran Madura. J Sains Seni Pomits 3 (2): 49-52. DOI: 10.12962/j23373520.v3i2.6869.

Bakhshi M. 2018. Molecular phylogeny and morphology of four Ramularia species from Iran along with a checklist of ramularia-like taxa. Rostaniha. $19 \quad$ (2): 92-112. DOI: 10.22092/BOTANY.2019.124392.1133.

Boyd DR, Sharma ND. Allen CCR. 2001. Aromatic dioxygenases: molecular biocatalysis and applications. Curr Opin Biotechnol 12 (6) 564-573. DOI: 10.1016/S0958-1669(01)00264-6.

Cong N, Thi L, Mai N, Thi C, Thanh VT, Nga LP, Minh NN. 2014. Application of a biofilm formed by a mixture of yeasts isolated in Vietnam to degrade aromatic hydrocarbon polluted wastewater collected from petroleum storage. Water Sci Technol 70 (2): 329-336. DOI: $10.2166 /$ wst.2014.233.

Fialova A, Boschke E, Bley T. 2004. Rapid monitoring of the biodegradation of phenol-like compounds by the yeast Candida maltosa using BOD measurements. Int Biodeter Biodegrad 54 (1): 69 76. DOI: 10.1016/j.ibiod.2004.02.004.
Gami AA, Shukor MY, Khalil KA, Dahalan FA, Khalid A, Ahmad SA. 2014. Phenol and phenolic compounds toxicity. J Environ Microbiol Toxicol 2 (1): 11-23.

Haigler BE, Wallace WH, Spain JC. 1994. Biodegradation of 2nitrotoluene by Pseudomonas sp strain JS42. Appl Environ Microbiol 60 (9): 3466-3469.

Heipieper HJ, Martínez M. 2010. Toxicity of hydrocarbons to Microorganisms. In: Timmis KN (ed.). Handbook of Hydrocarbon and Lipid Microbiology. Springer-Verlag, Berlin. DOI: 10.1007/9783-540-77587-4_108.

Heras-Vazquez L, Mingorance-Cazorla L, Clemente-Jimenez JM, Rodriguez-Vico F. 2003. Identification of yeast species from orange fruit and juice by RFLP and sequence analysis of the 5.8 S rRNA gene and the two internal transcribed spacers. FEMS Yeast Res 3 (1): 3-9. DOI: 10.1016/S1567-1356(02)00134-4.

Karimia M, Hassanshahian M. 2016. Isolation and characterization of phenol degrading yeasts from wastewater in the coking plant of Zarand, Kerman. Braz J Microbiol 47 (1): 18-24. DOI: 10.1016/j.bjm.2015.11.032

Kulbat K. 2016. The role of phenolic compounds in plant resistance. Biotechnol Food Sci 80 (2): 97-108.

Kumar S, Stecher G, Li M, Knyaz C, Tamura K. 2018. MEGA X: Molecular evolutionary genetics analysis across computing platforms. Mol Biol Evol 35 (6): 1547-1549. DOI: 10.1093/molbev/msy096.

Lõoke M, Kristjuhan K, Kristjuhan A. 2011. Extraction of genomic DNA from yeasts for PCR-based applications. Biotechniques 50 (5): 325328. DOI: $10.2144 / 000113672$.

Mäkelä MR, Marinović M, Nousiainen P, Liwanag AJ, Benoit I, et al. 2015. Aromatic metabolism of filamentous fungi in relation to the presence of aromatic compounds in plant biomass. Adv Appl Microbiol 91: 63-137.

Mulla SI, Hoskeri RS, Shouche YS, Ninnekar HZ. 2011. Biodegradation of 2-nitrotoluene by Micrococcus sp strain SMN-1. Biodegradation 22 (1): 95-102. DOI: 10.1007/s10532-010-9379-3. 
Rabinovitch-Deere CA, Parales RE. 2012. Three types of taxis used in the response of Acidovorax sp. strain JS42 to 2-nitrotoluene. App Environ Microbiol 78 (7): 2306-2315. DOI: 10.1128/AEM.07183-11.

Salmeron-Alcocer A, Ruiz-Ordaz N, Juarez-Ramirez C, Galíndez-Mayer J. 2007. Continuous biodegradation of single and mixed chlorophenols by a mixed microbial culture constituted by Burkholderia sp., Microbacterium phyllosphaerae, and Candida tropicalis. Biochem Eng J 37 (2): 201-211. DOI 10.1016/j.bej.2007.04.015.

Sanchez-García C, Alvarado-Capó Y, Acosta-Suárez M, Leiva-Mora M, Cruz-Martín M, Roque B. 2013. Quantification of phenols in lesions caused by Mycosphaerella fijiensis Morelet in 'Cavendish naine'. Rev Proteccíon Veg 28 (2): 149-152.

Schülter R, Schauer F. 2017. Biotransformation and detoxification of environmental pollutants with aromatic structures by yeasts. In: Satyanarayana T, Kunze G, editor. Yeast diversity in human welfare. Springer, Singapore. DOI: 10.1007/978-981-10-2621-8_13.

Seo JS, Keum YS, Li QX. 2009. Bacterial degradation of aromatic compounds. Int J Environ Res Public Health 6 (1): 278-309. DOI: 10.3390/ijerph6010278.

Sridevi V, Chandana Lakshmi MV V, Manasa M, Sravani M. 2012. Metabolic pathways for the biodegradation of phenol. Intl J Eng Sci Advan Technol 2(3):695-705.

Syed K, Porollo A, Lam YW, Grimmett PE, Yadav JS. 2013. CYP63A2, a catalytically versatile fungal P450 monooxygenase capable of oxidizing higher-molecular-weight polycyclic aromatic hydrocarbons, alkylphenols, and alkanes. Appl Environ Microbiol 79 (8): 26922702. DOI: 10.1128/AEM.03767-12.
Tetko IV, Gasteiger J, Todeschini R, Mauri A, Livingstone D, et al. 2005. Virtual computational chemistry laboratory - design and description. J Comput Aid Mol Des 19: 453-463. DOI: 10.1007/s10822-005-8694$\mathrm{y}$.

Thompson JD, Higgins DG, Gibson TJ. 1994. CLUSTAL W: improving the sensitivity of progressive multiple sequence alignment through sequence weighting, position-specific gap penalties and weight matrix choice. Nucleic Acids Res 22: 4673-4680. DOI: $10.1093 / \mathrm{nar} / 22.22 .4673$

Videira SI, Groenewald JZ, Braun U, Shin HD, Crous PW. 2016. All that glitters is not Ramularia. Stud Mycol 83: 149-163. DOI: 10.1016/j.simyco.2016.06.001.

Videira SIR, Groenewald JZ, Kolecka A, van Haren L, Boekhout T, Crous PW. 2015. Elucidating the Ramularia eucalypti species complex. Persoonia 34: 50-64. DOI: 10.3767/003158515X685670.

Walmsley RM, Keenan P. 2012. The eukaryote alternative: advantages of using yeasts in place of bacteria in microbial biosensor development. Biotechnol Bioprocess Eng 5 (6): 387-394. DOI: 10.1007/BF02931936.

Wartmann T, Kunze G. 2000. Genetic transformation and biotechnological application of the yeast Arxula adeninivorans. Appl Microbiol Biotechnol 54: 619-624. DOI: 10.1007/s002530000444.

Whang LM, Liu PW, Ma CC, Cheng SS. 2009. Application of rhamnolipid and surfactin for enhanced diesel biodegradationeffects of $\mathrm{pH}$ and ammonium addition. J Hazard Mat 164 (2-3): 1045 1050. DOI: 10.1016/j.jhazmat.2008.09.006. 